\title{
Avaliaçã̃o do Rendimento na Divulgação Governamental
}

\section{A Experiência da FUNAI}

\author{
LUIZ BELTRÃO \\ Professor do Centro Universitário de \\ Brasilia, Assessor do \\ Presidente da FUNAI, Escritor
}

Fazer Relações Públicas sem cumprir a etapa da avaliação do rendimento é desperdiçar trabaiho, mutilar um processo e malbaratar o dinheiro empregado na manutenção do pessoal e desenvolvimento dos programas adotados pela instituição para os seus públicos. Essa avaliação - considerada fundamental na atividade relacionista por Cutlip e outros teóricos ${ }^{1}$ - tem sido menosprezada por serviços e assessorias de RR.PP. no âmbito oficial: "Desconhecemos mesmo qualquer relatório, cientificamente tratado, de fonte governamental."

Parece-nos que todo o interêsse dêsses órgãos se concentra na divulgação, que não é senão uma fase do processo determinada pela investigação dos fatos e pela planificação dos programas. Observa-se o contrário nos setores de RR.PP. das emprêsas privadas, que dão a maior importância à avaliação. Talvez o fato seja uma decorrência de o Estado e seus departamentos não possuirem um setor específico de propaganda, o que acontece com organizações comerciais e industriais. Sendo nestas realmente estanques as atividades publicitária e relacionista, é forçoso que os serviços de RR.PP. se preocupem em fixar a importância do trabalho que executam através de uma apuração rigorosa e exata da atividade desenvolvida.

A avaliação do rendimento é uma análise dos resultados do programa e da eficácia da técnica empregada. Não mais se toma como ponto de partida os públicos; aqui, avalia-se criteriosaMadrid, Ediciones Rialp, 1961 
mente a atuação própria, respondendo-se às perguntas: - Qual foi o nosso trabalho? Deveríamos haver procedido de outra forma? Obtivemos resultados proporcionais aos esforços e gastos empregados? Quais os pontos positivos e quais os negativos que se apresentam? Que deveremos aconselhar à administração para corrigir as falhas e conseguir melhor desempenho?

RR.PP. NA FUNAI

Em meados de 1969, com a transferência da Fundação Nacional do índio (FUNAl) para Brasília, a convite do então Presidente, Jornalista Queiroz Campos, iniciamos a organização de um setor de Imprensa e Relações Públicas (hoje transformado em Assessoria de Relações Públicas), funcionando junto ao Gabinete da Presidência.

Dentro das limitações que nos eram impostas pelos Estatutos em vigor, limitamos as nossas atividades ao campo da difusão, orientando-a, contudo, para a pesquisa, uma vez que não acreditamos em RR.PP. sem um trabalho constante de investigação e avaliação.

Começamos pela análise morfológica e de conteúdo da imprensa diária e constatamos que o indio estava, como sempre estêve, em permanente presença como tema e objeto de notícias e comentários. Jornais e jornalistas se preocupavam, com freqüência, com os remanescentes dos primitivos habitantes do Brasil, sua sobrevivência e integração na comunidade nacional.

Êsse interêsse era revelado pelo espaço ponderável dado às atividades de pessoas e organismos que se dedicam à defesa do patrimônio indigena, à assistência aos silvícolas ou ao estudo de suas marcas históricas e pré-históricas e da influência cultural que exercem ou recebem em e de outras raças. Figuras de indigenistas, missionários, etnólogos, antropólogos e arqueólogos, médicos e enfermeiros, educadores, administradores e políticos, que participam da obra de conquista e integração do elemento indígena, perpassam pelas páginas dos periódicos, oferecendo o seu testemunho ou criticados em sua ação. E as notícias, as entrevistas, os artigos editoriais ou os comentários não são frios registros de ocorrências ou apreciações apenas mornas da atualidade indigenista mas recebem o calor $e$ a paixão que decorrem do nosso forte sentimento nativista e da participação efetiva do silvícola na formação étnica e cultural do homem brasileiro. 
Como o salientou o Diário de Notícias, da Guanabara: 2 "Em todos os países do mundo, o assunto índio é quente. Falase sôbre o índio brasileiro em qualquer jornal da Guanabara, São Paulo, ou de outra cidade importante, e logo de vários países da Europa chegam cartas e mais cartas, para as mais diversas fontes, sôbre os índios, pedem maiores detalhes das notícias, enfim, com o assunto índio a comunicação é fácil."

Natural, pois, que a FUNAI, órgão governamental encarregado da atração, conquista, tutela e integração do contingente indígena à comunidade nacional, tenha os seus projetos e atividades sob a constante atenção e vigilância da imprensa.

\section{SELEÇÃO E ANÁLISE}

Os órgãos diretivos da FUNAI necessitam, dêsse modo, de estar perfeitamente informados da imagem do organismo junto à opinião pública, refletida nos meios de divulgação, bem como da aceitação e repercussão obtida pelo material informativo e/ou esclarecedor acaso distribuído a êsses meios.

Para que essa visão fôsse real, deveríamos partir para uma análise da apresentação, ou seja, da morfologia e anatomia do jornal e do seu conteúdo. Pois, como ensina Jacques Kayser ${ }^{3}$, "uma e outra têm especialmente por objeto revelar o que um jornal quis comunicar aos seus leitores em informações e artigos, e presumir a influência que uma leitura normal do periódico exerceu no leitor". Assim, poderia o setor de RR.PP. fornecer elementos à Presidência e demais órgãos da FUNAI para cobrir as lacunas do noticiário, retificar dados e conceitos acaso mal entendidos pelas emprêsas jornalísticas, melhor divulgar a filosofia e ação do organismo e, ainda, tomar conhecimento das críticas e sugestões que the fôssem dirigidas pelos meios de informação e expressão da opinião pública.

Embora lutando com a pouca experiência do pessoal pôsto à nossa disposição para integrar o setor, durante o período julho/69 - junho/70, estabelecemos as bases da Assessoria, de Relações Públicas encarregadas, entre outras funções, de redigir e distribuir matéria informativa aos jornais e agências noticiosas com sede ou sucursal no DF, e colecionar, classificar, analisar e arquivar tudo quanto referente ao índio seja divulgado na imprensa diária do País.

2. Diário de Notícias - Guanabara, ed. 18-11-1970

3. KAYSER, Jacques - "Estudios de morfologia, de metodologia y de

Prensa Comparada" — Quito, CIESPAL, 1964 
Precisávamos realizar um levantamento exato: daí nasceram os dois primeiros estudos analíticos de morfologia e conteúdo, editados mimeogràficamente pela $\mathrm{FUNAI}$, em janeiro e em julho de 1970, e distribuídos aos setores de RR.PP. oficiais, universidades, emprêsas editoras e a quantos trabalham ou se interessam pela pesquisa em comunicação. ${ }^{4}$

\section{"O INDIO NA IMPRENSA DIÁRIA BRASILEIRA"}

$\mathrm{Na}$ impossibilidade de coletarmos os dados de tôda a imprensa diária brasileira, que conta com 259 órgãos, entre matutinos e vespertinos, ${ }^{5}$ selecionamos oito dos mais distinguidos e conceituados, levantando as suas características principais ( 2 ? semestre/1969) como por exemplo:

- "Jornal do Brasil" - matutino, 25 edições ao mês; edição média de 58 páginas; 432 centímetros de coluna por página; $55 \%$ de matéria redacional; ilustrado.

— "O Globo" (edição nacional) - vespertino, 25 edições ao mês; edição média de 17,6 páginas; 432 centímetros de coluna por página; $93 \%$ de superfície redacional; ilustrado.

- "O Estado de São Paulo" - matutino; 25 edições ao mês; edição média de 60,3 páginas; 432 centímetros de coluna por página; $27 \%$ de superficie editorial; ilustrado.

- "Correio Braziliense" - matutino; 25 edições ao mês; edição média de 23 páginas; 432 centímetros de coluna por página; $65 \%$ de matéria editorial; ilustrado.

Os jornais acima e mais o "Correio da Manhã", "O Jornal" e "Última Hora", do Rio, e a "Fôlha de São Paulo" ofereceram um total de 47.735 centímetros de coluna de matéria indigenista, correspondentes a 109 páginas de um jornal standard. Em espécie de composição, êsse total compreendeu:
Títulos ..............
$6.609 \mathrm{~cm} / \mathrm{col}$.
$(13,8 \%)$
Ilustrações
$9.839 \mathrm{~cm} / \mathrm{col}$.
$(20,5 \%)$
Texto
$30.687 \mathrm{~cm} / \mathrm{col}$.
$(66,7 \%)$

O número de matérias divulgadas foi de 1.024 , correspondendo, em média, a 2,6 matérias diárias, com uma superfície

4. "O Indio na imprensa diária brasileira" - Brasília, FUNAI, Janeiro de 1970 - e "O índio na imprensa diária brasileira - II" - Brasília, FUNAl, Julho de 1970 - edições mimeografadas.

5. Conforme "Anuário Estatístico do Brasil" - Rio, IBGE, 1969, com dados referentes ao ano de 1967. 
média de 130,7 centímetros de coluna, equivalente a pouco mais de um têrço de página. Registrou-se, entre o primeiro e o segundo semestre analisados, um aumento da superfície editorial ocupada pela matéria indigenista da ordem de $34,9 \%$.

Por seu turno, a análise de conteúdo demonstrou que o aumento verificado teve por causa principal a reação à campanha desencadeada do exterior, que nos apresentava como genocidas, empenhados no extermínio dos remanescentes indígenas. Com efeito, a maioria absoluta das matérias de fundo contrário à política indigenista brasileira, e que, no $2^{\circ}$ semestre de 1970 , veiculavam acusações ao nosso Govêrno da prática ou desídia na punição de crimes contra a incolumidade e a sobrevivência do silvícola, se originava de agências estrangeiras.

Para a análise de conteúdo, classificávamos as matérias quanto ao gênero jornalístico (notícias, entrevistas, reportagens, artigos e editoriais, chamadas, textos-legendas, "charges" e pesquisa); quanto às fontes fornecedoras de dados para a elaboração das matérias (FUNAI, redação, sucursais, agências, Ministério do Interior e outras); e quanto aos temas tratados (Assistência ao índio, Invasões e Conflitos, Influência Cultural, Expedições de Pacificação, Pesquisas Arqueológicas e Assuntos Gerais e Administrativos). Ao final do ano analisado (julho/69junho/70), registrávamos os seguintes resultados: das 1.024 matérias publicadas nos oito jornais analisados e em 806 edições, $601(53,9 \%)$ continham referência expressa à FUNAI. Para efeito de avaliação do seu caráter quanto à política indigenista, foram classificadas 674 matérias $(65,8 \%)$, não oriundas de fontes oficiais (FUNAI, Ministério do Interior e outros departamentos governamentais), registrando-se o seguinte resultado:

$\begin{array}{lrr}\text { matérias neutras } \ldots \ldots \ldots \ldots \ldots & 525 & (76,4 \%) \\ \text { matérias favoráveis } \ldots \ldots \ldots \ldots & 115 & (18,0 \%) \\ \text { matérias contrárias } \ldots \ldots \ldots \ldots & 34 & (5,6 \%)\end{array}$

A maioria das matérias era constituída de notícias $(54,6 \%)$; os gêneros opinativos (entrevistas, artigos e reportagens) alcançavam $40,3 \%$. A FUNAI fôra fonte de informações de 358 dessas matérias, com $34,9 \%$; as redações dos jornais e suas sucursais haviam originado 467 matérias $(45,5 \%)$ e as agências de notícias tinham distribuido 99 , que representavam $9,6 \%$.

Quanto aos temas, a assistência ao índio - sob cuja rubrica também incluímos quando se referiu à campanha difamatória antes citada - foi a tônica em 677 publicações $(66,2 \%)$, enquanto a segunda colocação cabia a informações sôbre invasão de território indígena e conflitos - 90 publicações $(8,7 \%)$. 
O balanço procedido nas matérias favoráveis à política indigenista nacional, cuja execução cabe à FUNAI, indicava que contávamos com uma opinião esclarecida e um apreciável suporte jornalístico, tanto que a maioria dos artigos, editoriais e entrevistas focalizava, num sentido de esclarecimento e defesa, o problema levantado de fora do País sôbre o tratamento que dávamos ao índio, repudiando as acusações de genocidio e etnocídio. Havia, entretanto, um aspecto que não nos parecia saudável e que poderia ser meta para um programa de RR.PP.: a imprensa dera mais importância e relêvo ao sensacionalismo dos choques e conflitos entre índios e civilizados do que ao trabalho paciente, tenaz e produtivo das expedições de pacificação dos sertanistas abnegados dos quadros da FUNAI.

\section{A NOVA META E SEU RESULTADO}

Em julho do ano passado, com a FUNAI sob a presidência do General Bandeira de Melo, era implantada a Assessoria de Relações Públicas, tendo como titular o Jornalista Afonso de Ligório Pires de Carvalho. As sugestões do Setor de Pesquisa foram adotadas e o fornecimento de dados para a imprensa e o material distribuído visaram conscientizar melhor o público quanto à ação do organismo no Programa de Integração Nacional, lançado pelo Presidente da República, e que tem o seu ponto de partida na abertura da Rodovia Transamazônica. Os primeiros seis meses da nova orientação ofereceram resultados apreciáveis, que estão contidos no relatório, que está sendo distribuído aos interessados pela FUNAI e que, em seguida, resumiremos. ${ }^{6}$

Foram selecionados dez diários, acrescentando-se aos já citados o "Diário de Notícias", da Guanabara, e "O Estado de Minas", de Belo Horizonte. Em 1.530 edições pesquisadas, foram encontradas, colecionadas e classificadas 404 matérias indigenistas, divulgadas em 318 edições, e que ocuparam uma superfície total de 21.427 centímetros de coluna, correspondentes a 49,9 páginas de um jornal standard. Em cada um dos 184 dias do semestre foram editadas, em média, 2,1 matérias, ocupando uma superfície de $116,4 \mathrm{~cm} / \mathrm{col}$., equivalente a quase um quarto de página diàriamente $(3,7)$. (V. Quadro A. e Gráfico Análise Morfológica.)

6. "A imprensa e a ação da FUNAI no Plano de Integração Nacional" - Brasilia, FUNAI, 1971 - em edição mimeografada. 


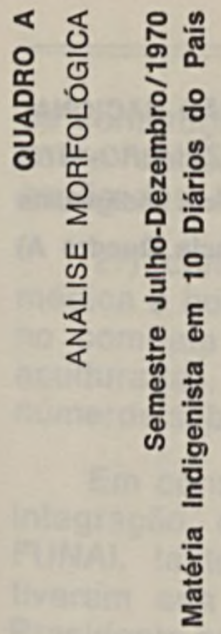

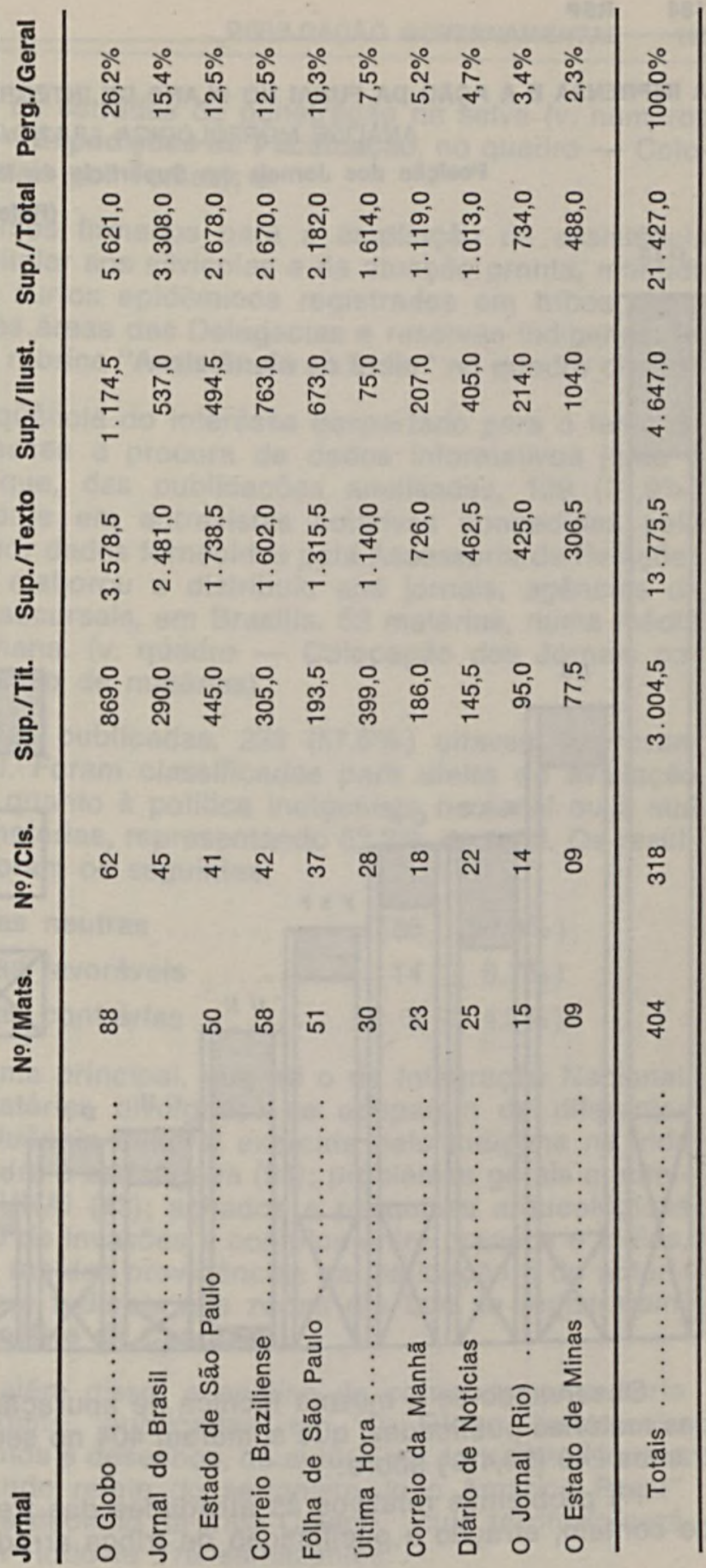


A IMPRENSA E A AÇÃO DA FUNAI NO PLANO DE INTEGRAÇÃO NACIONAL ANALISE MORFOLÓGICA (JULHO/DEZEMBRO-1970) Posição dos Jornais em Superfície de Matéria Indigenista (Referência Quadro A)

o $\mathrm{Gl}$.

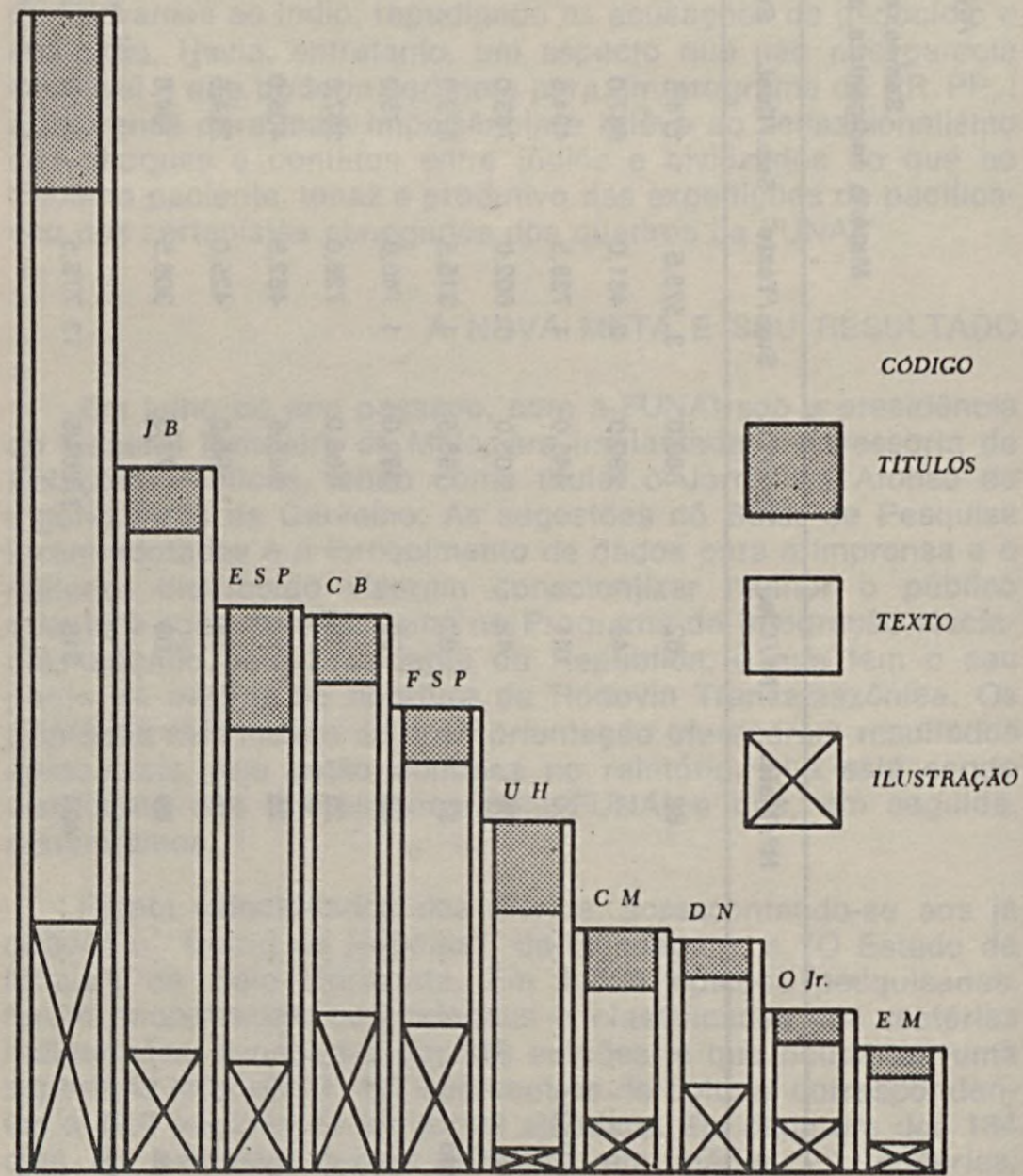

Observando-se a mesma técnica de apuração do conteúdo das matérias publicadas, que somaram 404 no semestre, encontramos $240(59,4 \%)$ sôbre:

19) problemas relativos às atividades das frentes pioneiras de contato, atração e pacificação de tribos arredias, nas áreas 
de construção de estradas de penetração na selva (v. números sob a rubrica - Expedições de Pacificação, no quadro - Colocação dos Jornais por Temas); e

20) convênios firmados para a ampliação da assistência médica e hospitalar aos silvícolas e da atuação pronta, mantida no combate a surtos epidêmicos registrados em tribos semiaculturadas, nas áreas das Delegacias e reservas indígenas. (v. números sob a rubrica "Assistência ao Índio" no quadro citado).

Em conseqüência do interêsse despertado para o tema da integração, cresceu a procura de dados informativos junto à FUNAI, tanto que, das publicações analisadas, $129(31,9 \%)$ tiveram sua fonte em entrevistas coletivas concedidas pelo Presidente ou por dados fornecidos pela Assessoria de Relações Públicas. Esta elaborou e distribuiu aos jornais, agências de informações e sucursais, em Brasilia, 52 matérias, numa média de 2,2 por semana. (v. quadro - Colocação dos Jornais por fontes de captação de matérias).

Das matérias publicadas, $233(57,6 \%)$ citavam expressamente a FUNAI. Foram classificadas para efeito de avaliação do seu caráter quanto à política indigenista nacional ou à sua execução 209 matérias, representando $52,2 \%$ do total. Os resultados obtidos foram os seguintes:

$\begin{array}{lrr}\text { matérias neutras } \ldots \ldots \ldots \ldots & 186 & (89,0 \%) \\ \text { matérias favoráveis } \ldots \ldots \ldots & 14 & (6,7 \%) \\ \text { matérias contrárias } \ldots \ldots \ldots \ldots & 9 & (4,3 \%)\end{array}$

Além do tema principal, que foi o da Integração Nacional, as restantes matérias divulgadas se ocuparam de diferentes aspectos da influência cultural exercida pelo indígena na vida civilizada brasileira e estrangeira (98); problemas gerais e administrativos da FUNAI (43); achados e pesquisas arqueológicas (13) e apenas 10 de invasões e conflitos entre brancos e índios, que requereram rápidas providências da instituição e de autoridades estaduais e federais nas zonas em que se registraram. (v. Gráfico - Análise de Conteúdo).

Constatou, além disso, a análise de conteúdo, uma série de 20 reportagens, publicadas em O Globo fartamente ilustradas com fotos e desenhos, de autoria do Jornalista Nonato Machado, "segundo relato do sertanista João Américo Peret" sôbre a história e declínio da tribo Caiapó, "cujo território será atravessado pela Rodovia Transamazônica". 


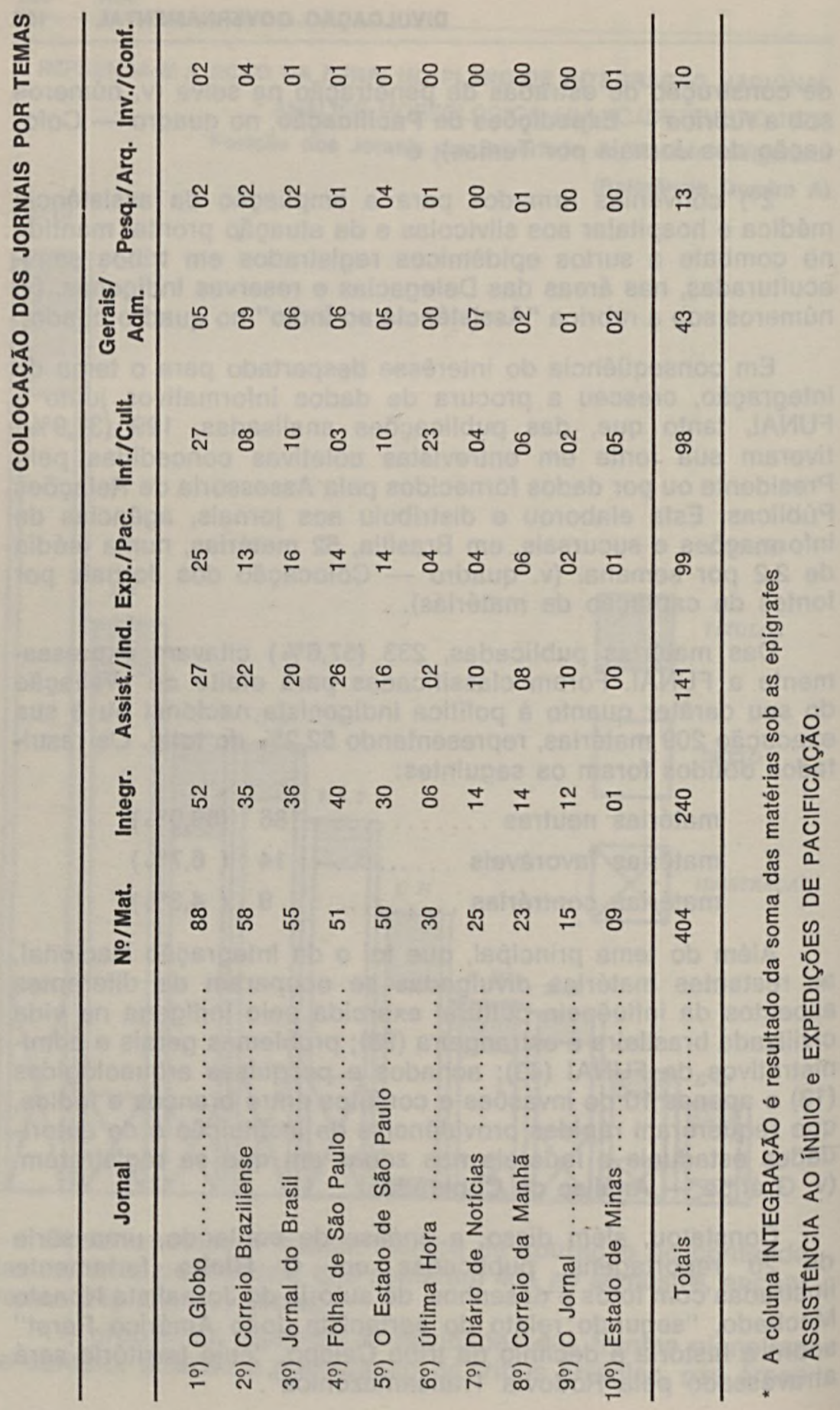




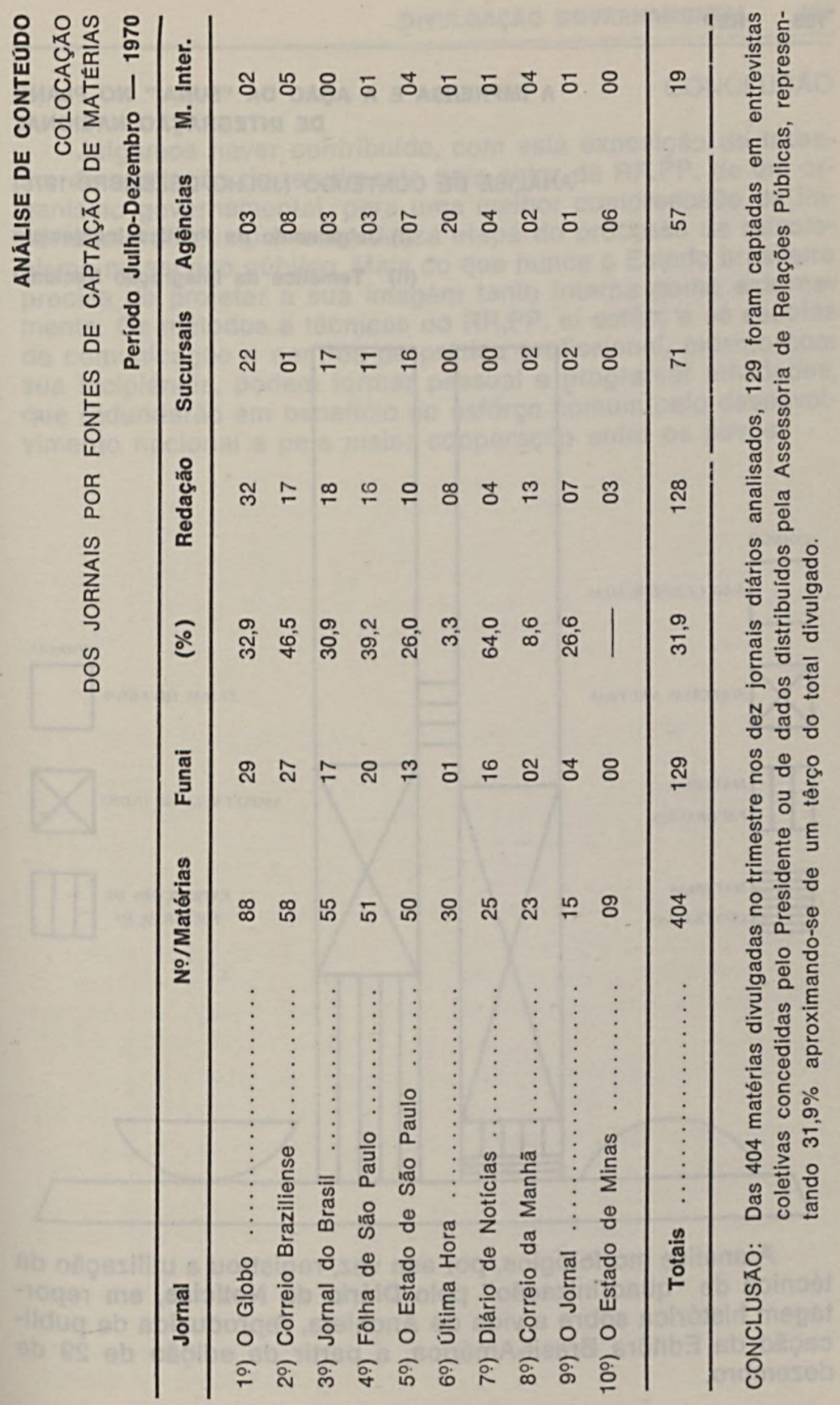


A IMPRENSA E A AÇÃO DA "FUNAI" NO PLANO DE INTEGRAÇÃO NACIONAL

ANÁLISE DE CONTEÚDO (JULHO/DEZEMBRO-1970)

(I) Julgamento da Política Indigenista

(II) Temática da Integração Nacional
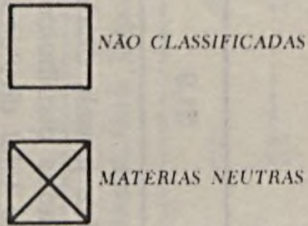

MATERIAS NEUTRAS

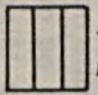

MATERLAS

FAVORAVEIS

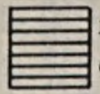

MATERIAS

CONTRARIAS

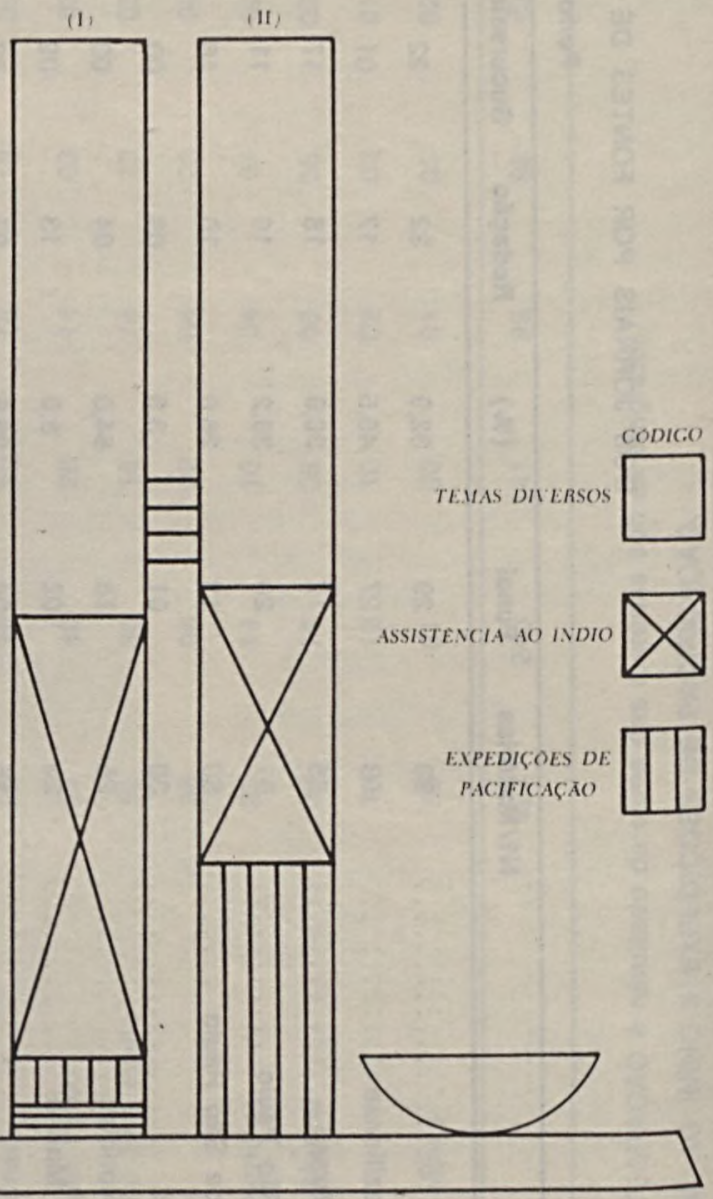

A análise morfológica, por sua vez, registrou a utilização da técnica de "quadrinização" pelo Diário de Notícias, em reportagem histórica sôbre a vida de Anchieta, reproduzida de publicação da Editôra Brasil-América, a partir da edição de 29 de dezembro. 


\section{CONCLUSÃO}

Julgamos haver contribuído, com esta exposição de trabatho de avaliação de rendimento pelo setor de RR.PP. de um organismo governamental, para uma melhor compreensão da importância do cumprimento dessa etapa do processo de relacionismo no serviço público. Mais do que nunca o Estado brasileiro precisa de projetar a sua imagem tanto interna como externamente. Os métodos e técnicas do RR.PP. eí estão, e as escolas de comunicação e centros de prática profissional, mesmo com sua incipiência, podem formar pessoal e programar atividades, que redundarão em benefício do esfôrço comum pelo desenvolvimento nacional e pela maior cooperação entre os povos. 
